Direitos autorais distribuídos a partir $\mathrm{d}$ licença Creative Commons (CC BY-NC-SA - 4.0)

\title{
ESTÉTICA DE GLAUBER ROCHA E AS INTERFACES COM O CINEMA DOCUMENTÁRIO
}

\author{
Rosselane Giordani - rosselanegiordani76@gmail.com \\ Universidade Estadual do Oeste do Paraná, Unioeste, Cascavel, Paraná, Brasil; https://orcid.org/0000-0002-5246-1955
}

\begin{abstract}
RESUMO: Este estudo pretende refletir sobre alguns aspectos da estética cinematográfica de Glauber Rocha, olhando especificamente para as confluências que se estabelecem com a estética do cinema documentário. A intenção é problematizar como Glauber Rocha se apropria da linguagem documental para compor sua estética do real e materializar seu projeto poético e político em um tempo histórico e cultural que ficou conhecido pela efervescência da produção de uma arte de viés e tom extremamente político que buscava desvelar a realidade do povo brasileiro e sua identidade frente ao colonialismo cultural norte-americano. $\mathrm{O}$ pensamento do intelectual e cineasta baiano está impregnado justamente do espírito dessa época em que a produção da arte contemporânea passa por uma profunda mudança tanto no Brasil como na Europa, onde os artistas redefiniram suas estéticas entrelaçando-as com causas políticas e por sua vez empenhados em colocar a arte a serviço da mudança social. A estética do real que 'soprava ventos' nas vanguardas europeias reverberava no Brasil nos anos de 1960, sendo remodulada pela ótica glauberiana, introduzindo o povo brasileiro e suas realidades no novo cinema brasileiro. A estreita relação, e porque não dizer uma relação visceral, entre Cinema Novo e a busca por uma estética do real nos leva a refletir de que modo a diluição das fronteiras entre o cinema ficcional e o documentário reverberou e influenciou a composição da linguagem do Cinema Novo no Brasil. Para as reflexões tomamos como referência Nicholls (2005), Penafria (1999), Xavier (2001) e Simonard (2003).
\end{abstract}

PALAVRAS-CHAVE: Cinema Novo; Glauber Rocha; documentário.

\section{INTRODUÇÃO}

A figura do cineasta baiano Glauber Rocha para muitos brasileiros, sejam pesquisadores, intelectuais ou apreciadores da arte, é reconhecida como uma das grandes expressões do movimento político-cultural conhecido como Cinema Novo. Esse 'lugar' que Glauber ocupa na memória dos brasileiros e na história da produção cultural nacional tem relação direta com a singularidade do conjunto da sua obra que criou uma estética política no modo de pensar e fazer cinema no Brasil, em um tempo em que se discutia a ideia de se criar um cinema nacional que tivesse o compromisso de mostrar o Brasil e problematizar a sua identidade político-cultural frente ao colonialismo, principalmente do cinema norteamericano. Glauber se propunha a realizar um cinema político-reflexivo que tensionasse um movimento de ruptura frente ao colonialismo da indústria cultural cinematográfica, mas, sobretudo, um ato político sobre o processo social.

Este estudo pretende refletir sobre a estética cinematográfica glauberiana, olhando especificamente para as confluências que se estabelecem com a estética do cinema documentário, sem a pretensão de esgotar o assunto. A intenção é problematizar como Glauber Rocha se apropria da 
linguagem documental para compor sua estética do real e materializar seu projeto poético e político, pois ele compreende que o papel do artista verdadeiramente revolucionário é colocar sua arte à disposição da transformação da sociedade e não oferecer meramente um artefato para deleite estético.

É preciso dizer que esse pensamento do intelectual e cineasta baiano está impregnado justamente do espírito dessa época em que a produção da arte contemporânea passa por uma profunda mudança tanto no Brasil como na Europa, onde os artistas redefiniram suas estéticas entrelaçando-as com causas políticas e por sua vez empenhados em colocar a arte a serviço da mudança social. As vanguardas europeias procuravam subverter a tradição da teoria da arte expressando uma rebelião ao introduzir objetos da vida real e estabelecer por assim um novo 'cânone' que mistura linguagens e estilos, que entrelaça meios e formas de expressões, nas quais se redefiniram os próprios artistas, suas linguagens e a própria arte, própria ao tempo de caos e transformações do pensamento social-político e cultural da época. No Brasil, o Tropicalismo e o Cinema Novo, para citar somente duas grandes expressões culturais da época, expressavam o movimento de se pensar a arte em relação ao social, neste caso à realidade sóciocultural brasileira. Movimentos artísticos e políticos seguiam a tendência de transformação e reelaboração do fazer artístico contemporâneo forjado pelo encontro das artes com o real e também das interfaces e diálogos entre as artes. Desse modo, a arte contemporânea passa a se traduzir em movimentos intra e inter-artes, como também é o caso do Cinema Novo o qual Glauber Rocha é referência.

\section{CINEMA NOVO E O CONTEXTO BRASILEIRO}

Um breve relato do contexto histórico se faz relevante nesse estudo para podermos compreendermos a sua relação com a produção cultural do novo cinema brasileiro, o qual o cineasta Glauber Rocha foi um dos grandes nomes a encampar um novo modo de fazer cinema no Brasil, tanto em termos de linguagem quanto de um olhar que priorizasse a realidade sócio cultural brasileira e a sua diversidade.

Durante os anos 50 e começo dos anos 60 o Brasil sofreu um intenso processo de industrialização com resultados sociais contraditórios. O perfil econômico da sociedade brasileira se transformava de agrário-exportador para industrial, o que influenciou no processo de urbanização causada pela migração de milhões de pessoas do campo para as cidades, acentuadamente nas cidades do Rio de Janeiro e São Paulo. Nesse contexto, intelectuais passaram a aderir a uma leitura da realidade brasileira que caracterizava o país como subdesenvolvido e culturalmente colonizado. Por sua vez, eles compreendiam que a produção cultural teria papel determinante no processo de afirmação do que era a cultura nacional, fazendo frente a uma cultura dominante na qual a burguesia e as camadas urbanas guiavam seu comportamento por aquilo que era ditado pela produção cultural estrangeira, principalmente pelo cinema 
de Hollywood. Assim, mais uma vez o sentimento nacionalista e a busca por algo genuinamente próprio à cultura brasileira - como as ideias advindas do Movimento Modernista nascido nos anos de 1920 resgataram o pensamento de que era preciso buscar o caráter nacional, o brasileiro frente às produções estrangeiras de modo que o cinema brasileiro ocupasse mais espaço e conseguisse tomar uma fatia do mercado consumidor de cinema.

Simonard (2003) alerta que os cinemanovistas não foram os primeiros a perceberem a importância de se lutar por um cinema brasileiro forte, com uma linguagem própria. Uma geração anterior já havia começado a articular, no começo da década de 50, uma crítica sobre o cinema brasileiro que questionava a dependência do mercado brasileiro aos filmes importados, a submissão do cineasta no Brasil à linguagem do cinema produzido em Hollywood; geração essa que começou a lutar para que o cinema nacional se tornasse uma das expressões da cultura brasileira, o que depois foi encampado pelo Cinema Novo.

O novo cinema brasileiro que surge com o movimento do Cinema Novo tem então como ponto de partida um mergulho na realidade sócio-político-cultural brasileira, do mesmo modo que foi proposto pelo movimento Modernista de 1922. Xavier (1989) vai dizer que os cinemanovistas acreditavam que lutar pela cultura nacional significava lutar pela libertação nacional que torna possível a construção de uma cultura. Isso porque o Brasil era visto como um país colonizado culturalmente, característica esta muito marcante com relação ao cinema. O movimento defendia que o filme nacional ocupasse o lugar do produto estrangeiro. Maria Rita Galvão e Jean-Claude Bernardet analisam a "situação colonial" do cinema brasileiro:

O fator básico que explica a "situação colonial" do cinema brasileiro é o fato de que o "produto importado" ocupa o seu lugar. Trata-se, portanto, de uma definição de ordem econômica que será metaforicamente transposta para o campo da cultura. Importamos não apenas objetos manufaturados, mas idéias prontas - e formas, modelos, estruturas de pensamento - forjadas em função de realidades diversas que correspondem mal a nossa própria realidade. Estas idéias ocupam um tal espaço em nossas mentes que pouco sobra para que nelas se desenvolvam idéias próprias. Além de produtos industriais, os filmes são também produtos culturais. Juntamente com os filmes, importamos uma concepção de cultura - e uma concepção de cinema que identifica com o próprio cinema o cinema estrangeiro. Nisto reside o cerne da "colonização" cultural: a "situação colonial" - cuja marca cruel e inescapável é a mediocridade - se configura quando se adota um modelo importado que não se tem condições de igualar (GALVÃO; BERNARDET, 1980, p. 166-167).

A crítica ao colonialismo era uma questão central e um dos grandes temas políticos que dominavam a pauta dos intelectuais de esquerda no mundo juntamente com as guerras nacionais antiimperialistas. Assim, o pensamento crítico da esfera política foi transposto para a esfera cultural e serviu de inspiração e pressuposto para o desenvolvimento do Cinema Novo que defendia a criação de um 
cinema nacional. Em carta a Paulo César Saraceni, Glauber Rocha expressa sua vontade em lançar o movimento.

Escrevi um artigo negando o cinema. Não acredito no cinema, mas não posso viver sem o cinema. Acho que devemos fazer revolução. Cuba é um acontecimento que me levou às ruas, me deixou sem dormir. Precisamos fazer a nossa aqui. Cuba é o máximo [...]. Estão fazendo um novo cinema [...], vários filmes longos e curtos. Estou articulando com eles um congresso latino-americano de cinema independente. Vamos agir em bloco, fazendo política. Agora, neste momento, não credito nada à palavra arte neste país subdesenvolvido. Precisamos quebrar tudo. Do contrário eu me suicido (SARACENI, 1993, p. 101).

Analisando os sentidos dessa carta é possível dizer que Glauber demonstra um posicionamento político que associa a criação de um cinema nacional às lutas anti-imperialistas. Glauber também faz uma crítica feroz as produções ${ }^{1}$ que copiavam o modelo de cinema comercial americano e as chanchadas da Atlântida, defendendo a criação de um estilo próprio para o cinema nacional.

Nosso cinema é novo porque o homem brasileiro é novo e a problemática do Brasil é nova e nossa luz é nova e por isso nossos filmes nascem diferentes dos cinemas da Europa" [...]. Nossa geração tem consciência: sabe o que deseja. Queremos fazer filmes antiindustriais [...] (ROCHA, 1981, p. 17).

Nesse sentido Saraceni também vai dizer que o Cinema Novo propunha um cinema antiindustrial, "aberto, sem nenhum dogma, nenhum preconceito, [...] autoral, sincero, criativo, revolucionário e que olhasse a realidade social e econômica do Brasil com vontade de analisá-la, transformá-la num mundo melhor para todos" (1993, p. 118). O movimento se propunha a desnudar a realidade brasileira, mais dramática e profunda, uma realidade que costumava ser embelezada e maquiada para o entretenimento das elites. Silva Júnior (2016) dirá que "a estratégia do Cinema Novo era criar filmes baratos, explosivos, bárbaros, radicais, antinaturalistas e polêmicos”, e possibilitar a utilização de uma linguagem fundada na liberdade, numa vanguarda experimental orientada pela ideia de transmitir um recorte da realidade no qual a câmera na mão é um instrumento de escritura do real podendo romper com marcações prévias e artifícios de filmagem esquematizados, fundando uma estética do real.

\section{A ESTÉTICA DO REAL: REVERBERAÇÕES DO CINEMA DOCUMENTÁRIO}

A estreita relação, e porque não dizer uma relação visceral, entre Cinema Novo e a busca por uma estética do real nos leva a refletir de que modo ao longo da história do cinema a diluição das fronteiras

\footnotetext{
${ }^{1}$ No Brasil dos anos 50 e 60 fazer bons filmes era sinônimo de fazer filmes nos moldes do cinema estrangeiro de "qualidade", feito por Hollywood e pelos cinemas industriais europeus.
}

Travessias, Cascavel, v. 15, n. 2, p. 145-159, maio/ago. 2021. DOI: https://doi.org/10.48075/rt.v15i2.27757 
entre o cinema ficcional e o documentário e seu caráter realista reverberou e influenciou a composição da linguagem do Cinema Novo no Brasil.

Silva Júnior (2013) dirá que a antiga dicotomia entre filme documentário e o filme de ficção passou a ter uma linha divisória mais tênue a partir das inovações estilísticas e as novas formas de apreensão do real pelo cinema, que se tornaram agudas marcadamente pela atuação das estéticas do Cinema Soviético da década de 1920, com a ideia de que o cineasta participa da situação registrada onde se estabelece uma relação. O pesquisador citará também a contribuição da Nouvelle-Vague francesa nas décadas 1950 e 1960 e o Neo-Realismo italiano - que permitiu uma aproximação com os fatos da realidade, e retratou o pós-guerra na Itália.

Os diretores desses cinemas tinham como meta construir uma montagem que negasse o filme clássico, de narrativa linear. Essas vanguardas estéticas buscavam criar novas linguagens ampliando a capacidade expressiva, de modo que tanto diretores de filmes de ficção quanto diretores de filmes documentários utilizassem recursos técnicos e estéticos das duas modalidades cinematográficas em suas obras, buscando uma relação mais estreita com o real, o que levou muitas vezes à intervenção do cineasta na própria representação fílmica, o que ocorreu em especial no documentário especialmente na classificação elaborada por Bill Nichols (2005), que seria chamado modo participativo e modo reflexivo. Neste ponto precisamos detalhar de que modo 'a posição' do cineasta muda na construção da representação da realidade, pois isto implica num novo modo de fazer cinema.

O cinema documental de modo participativo - derivado de ideias de pesquisa participativa vindas das ciências sociais e da antropologia - dá-nos uma ideia do que é, para o cineasta, estar numa determinada situação e como aquela situação consequentemente se altera; é possível perceber a posição e o engajamento ativo do cineasta e sua experiência sob o real. Nesta posição o cineasta não observa discretamente, ele é um “ator social” que está "na cena”. O documentário participativo pode enfatizar o encontro real, vivido entre cineasta e tema. Deste modo, o cineasta assume papel acentuado, desde o ato físico de captar a imagem até o ato político de unir forças com aqueles que representam seus temas. A construção da narrativa fílmica se faz então por meio de uma experiência etnográfica, de vivência e aproximação com a experiência a ser representada, do encontro e interação entre o cineasta e as pessoas que representam seu tema. Neste modo a intenção é então aguçar nossa percepção e consciência sobre a construção da representação da realidade.

Nichols observa que se no modo participativo o mundo histórico provê o ponto de encontro para os processos de negociação entre cineasta e participante do filme, já no modo reflexivo são os processos de negociação entre cineasta e espectador que se tornam foco de atenção. "Em vez de seguir o cineasta em seu relacionamento com outros atores sociais, nós agora acompanhamos o relacionamento do cineasta 
conosco, falando não só do mundo histórico como também dos problemas e questões da representação" (NICHOLS, 2005, p. 162).

O modo reflexivo nos impulsiona a pensar justamente como é feito o processo de representação da realidade, ou seja, nos remete para o tempo anterior à obra, nos provocando a refletir sobre como representamos o mundo histórico e também como ele está sendo representado. Esse tempo anterior à obra, é o tempo no qual o cineasta interagiu com a realidade a ser representada e com seus personagens, é o tempo no qual ele se aproximou e vivenciou a realidade, para a partir daí criar a representação fílmica dessa realidade, desse modo a realidade influencia o ato de criação.

Numa relação 'quase' que simbiótica, a linguagem documental acrescenta à narrativa ficcional uma potência à representação do real. De modo que esse processo de hibridização da linguagem fílmica além de acentuar a diluição de fronteiras configurou uma nova perspectiva para o cineasta se posicionar e construir representações sobre o real histórico, compondo um novo cinema. No Brasil, o novo cinema é o Cinema Novo, no contexto dos países subdesenvolvidos, colonizados. Silva Júnior vai dizer que enquanto na Europa o novo cinema era a expressão de uma nova estética pela qual passaram o cinema europeu, mas também o norte-americano e japonês nos anos de 1950 e 1960, o Cinema Novo brasileiro é “a realização desse novo cinema, seja ela técnica, formal ou estética, no cinema dos países pobres, com as especificidades dessas nações, abordando questões próprias” (2013, p. 128).

O movimento de potencialização dos filmes híbridos tanto na Europa quanto no Brasil tem em alguma medida relação com a linguagem do cinema documentário. Por isso estabelecemos confluências com o Cinema Novo e com a composição da estética glauberiana, que resultou na formulação de um projeto estético multifacetado.

\subsection{O REAL NA ESTÉTICA GLAUBERIANA: HIBRIDIZAÇÕES COM A LINGUAGEM DOCUMENTAL}

O Cinema Novo no Brasil estava inserido no contexto do imaginário revolucionário da época e seus realizadores estavam interessados em influir no processo político de modo a colocar a arte como um instrumento de revolução. Seus temas perpassavam desde a pobreza, a ditadura militar, a guerrilha, o desenvolvimento e o subdesenvolvimento, e seu ideário incorporou pensamentos advindos, dentre outras manifestações, da literatura do ciclo regional de 30 a 45, por entender que esses autores denunciavam a miséria do ponto de vista social e cabia ao cinema com a força das imagens exibir as condições de miserabilidade, um recorte que suscitasse o debate político. Enfoque este também inspirado principalmente em Bertold Brecht, que ele havia lido na faculdade de Belas Artes, além de inspirações vindas do movimento do Tropicalismo. 
O pensamento dos cinemanovistas se debruçava então sob a denúncia da pobreza, mas não somente nas temáticas abordadas, como também na forma, no fazer cinematográfico que evidenciasse deficiências técnicas como uma fotografia suja, e nos problemas de montagem. Assim, o subdesenvolvimento é incorporado ao cinema de um modo aguçado aproximando visceralmente o modo de fazer cinema à realidade brasileira e expondo as condições do fazer cinematográfico.

O tom de denúncia perseguia a intenção de compreender as origens das condições sociais, e para isso Glauber Rocha coloca sua produção muito próxima ao cinema documentário, mesmo quando realiza uma obra ficcional. Ele defende o documentário como prática para a construção do filme ficcional, como meio de aproximação com a realidade reelaborada pela estética fílmica. Nesse sentido Glauber adota estratégias próximas àquilo que Nichols denomina como documentário de modo participativo e reflexivo. O cineasta se coloca como um ator social no contexto da produção. Silva Júnior (2006) dirá que a cinematografia de Glauber explicita a sua estreita relação com o filme documentário pelas filmagens externas, luz natural, parte do elenco formada por moradores locais da filmagem onde o filme foi realizado.

A partir da filmografia glauberiana extraímos a obra Barravento (1961) para analisarmos elementos da linguagem documental que permeiam a estética do cineasta. Glauber irá afirmar que essa obra tinha um tom de denúncia e crítica à alienação de negros frente à relação mítica com a religiosidade expressa no candomblé. No 'encontro' com a realidade da comunidade de Buraquinho no interior da Bahia o cineasta buscará representar e construir um discurso político sobre a necessidade de libertação da exploração dos pescadores que se mantém por meio da religiosidade que cega e mantém a comunidade refém da alienação e por sua vez da pobreza e miséria.

As filmagens de Barravento em uma pequena comunidade pesqueira na praia de Buraquinho (Salvador/Bahia), iniciaram sob a direção e roteiro de Luiz Paulino dos Santos. Glauber Rocha era, então, o produtor executivo, responsável pela realização do filme. A ideia de Paulino era fazer um drama praieiro, de amor e de mar. Era a história de uma mulher branca que vivia numa aldeia de pescadores negros que se apaixona por um rapaz negro recém-chegado da cidade. Mas, as filmagens passaram por vários problemas, até que Glauber resolveu assumir a direção. A princípio, Glauber seguiu o roteiro de Paulino, mas esse roteiro acabou por se perder. Silva Júnior (2016) dirá que o enfoque dado por Paulinho era considerado conformista com os ritos do candomblé e do misticismo, o que não correspondia à estética crítica e à política que Glauber procurava. Assim o drama de amor entre uma branca e um negro se transformou em uma denúncia do misticismo, da passividade e da miséria dos pescadores negros. Com Barravento, Glauber viu que o cinema podia ser um meio de transmissão de ideias políticas e sociais.

Pelas mãos de Glauber o filme se transformou num manifesto contra a pobreza e a exploração. Barravento é a história de uma comunidade de pescadores de xaréu, explorada pelo dono da rede e pelo 
Mestre responsável por organizar o grupo para a pesca e depois para a partilha do peixe. A comunidade explorada encontra felicidade nas rodas de samba e de capoeira, e na religiosidade encontra a explicação para o sistema que se estabelece na relação com as condições materiais de existência e sobrevivência dos pescadores, o que os mantém segundo o argumento do filme subjugados e alienados de sua condição material e da possibilidade de ruptura e mudança. A comunidade acredita que Aruã é protegido de Iemanjá e enquanto se mantiver virgem, como um noivo para a Rainha das Águas, ela irá proteger os pescadores. Por acreditarem nesse mito, esses homens enfrentam o mar e todas as adversidades que a vida lhes impõe. Essa ordem será desestabilizada com a chegada de Firmino que vem para subverter a fé pela crença na mudança por meio da ação e da tomada de consciência do pescador. Firmino é um exmorador do povoado que foi ganhar a vida na cidade, e ao retornar à comunidade quer romper com as crenças e o sistema de escravidão que os pescadores estão submetidos. Ele insufla os pescadores contra o "estado de alienação" que se dá pela crença em Iemanjá e a exploração do Mestre e do patrão, identificados como os responsáveis pela miséria daquele grupo. O argumento de Glauber será então mostrar o quanto esse povo era enganado e espoliado por ser místico, por acreditar em Iemanjá, por serem tão apegados ao candomblé.

Em artigo publicado no Diário de Notícias em 1969, Glauber revela que filmar Barravento o colocou frente à frente com a miséria que conhecia apenas pelos livros. Diante de tanta fome e de tanta miséria, o cinema, num país como o Brasil, não poderia ser apenas arte. Dessa forma, Glauber se aproximava do neorealismo italiano, num cinema engajado político-socialmente, naquilo que ele mesmo iria chamar de nouvelle vague caipira.

Logo no início do longa-metragem é possível perceber o entrelaçamento com a linguagem documental no sentido de representar a realidade brasileira. O filme inicia com um texto explicando a situação histórica, geográfica e social do lugar, expressando o ponto de partida sobre a realidade social a ser representada, trazendo elementos com o objetivo de informar e descrever a realidade da comunidade onde se passará a narrativa e as condições em que se encontra num modo crítico e reflexivo de leitura sobre o real. Barravento inicia com uma explicação, que antecipa a forma de como a religiosidade afrodescendente será tratada no filme.

No litoral da Bahia vivem os negros puxadores de xaréu, cujos antepassados vieram escravos da África. Permanecem até hoje os cultos aos deuses africanos e todo esse povo é dominado por um misticismo trágico e fatalista. Aceitam a miséria, o analfabetismo e a exploração com a passividade característica daqueles que esperam o reino divino. Iemanjá é a rainha das águas, a velha mãe de Irecê, senhora do mar que ama, guarda e castiga os pescadores. Barravento é o momento de violência, quando as coisas da terra e mar se transformam, quando no amor, na vida e no meio social ocorrem súbitas mudanças. Todos os personagens apresentados no filme não têm relação com pessoas vivas ou mortas 
e isto será apenas mera coincidência. Os fatos, contudo existem. Barravento foi realizado numa aldeia de pescadores na praia de Buraquinho, alguns quilômetros depois de Itapuã, Bahia (BARRAVENTO, 1961, n.p.).

A voz documental do narrador revela a posição do diretor na/sobre a narrativa e apresenta o argumento transmitindo um ponto de vista e a perspectiva que será desenvolvida. Ao demarcar seu ponto de vista a voz revela como seu criador se engaja no mundo e se posiciona politicamente sobre a realidade representada. Ao filmar Barravento em uma experiência que poderia se dizer etnográfica junto à comunidade, Glauber vai afirmar que os dias que havia passado em Buraquinho foram mais ricos que todos os estudos que havia desenvolvido, e ao se defrontar com a realidade crua ele se engaja e adota um posicionamento crítico que vai externar na obra fílmica.

Nichols (2005) dirá que a voz do documentário atesta o caráter de cineasta como ele se posiciona diante da realidade social e também sua visão criativa, ou seja, ela revela o ponto de vista social do cineasta e como ele se revela no ato de criar. "A voz do documentário fala através de todos os meios disponíveis para o criador. Esses meios podem ser resumidos como seleção e arranjo de som e imagem, isto é, a elaboração de uma lógica organizadora para o filme (2005, p. 76). Desta forma o cinema documentário não só representa a realidade social, como a re-apresenta do ponto de vista particular da realização. Ou seja: “a evidência da re-apresentação sustenta o argumento ou perspectiva da representação.

Em Barravento, Glauber posiciona de início seu olhar sob a realidade social e revela a seu modo como compreende a religiosidade como um elemento de opressão. Ideia essa que pode ser captada também por meio de carta que Glauber escreveu a Paulo Emílio Salles Gomes (1960), na qual ele reforça a ideia de religiosidade alienante, sendo ainda mais contundente em seu posicionamento contra o candomblé:

[...] esprimido o roteiro, restaram personagens reais, primitivos e intensamente povoados de misticismo: [...] miseráveis, analfabetos, escravos, corajosos para enfrentar mar bravo mais covardes para defender os direitos de trabalho na pesca do xaréu eles afogam a fome nos exóticos candomblés baianos. Estes candomblés, embora possuam valor cultural estimável, adormecem uma raça de fantásticas possibilidades contudo, que o povo negro sacrifique uma perspectiva em função de uma alegoria mística. Barravento é um filme contra os candomblés, contra os mitos tradicionais, contra o homem que procura na religião o apoio e a esperança. [...] Apaixonado que sou pelos costumes populares, não aceito... (BENTES, 1997, p. 125-126).

Um fragmento do filme que expressa a crítica a religiosidade de forma mais evidente e reforça a voz do cineasta na obra é uma das falas de Firmino um dos personagens principais do filme no trecho que inicia aos $28 \mathrm{~min} 25 \mathrm{~s}$ e segue até $28 \mathrm{~min} 46 \mathrm{~s}$ : 
Trabalha cambada de besta, trabalha! Preto veio para essa terra pra sofre, trabalha muito e não come nada, nada não. Menos eu que sou independente. Já larguei esse negócio de religião. Candomblé não resolve nada. Precisamos lutar, resistir. Nossa hora tá chegando irmão! (BARRAVENTO, 1961, n.p.).

A crítica de Glauber não se concentra somente ao caráter alienador da religião, mas também a exploração do branco proprietário da rede e a miséria que os pescadores da aldeia são submetidos e isso pode ser percebido nos diálogos dos personagens em alguns trechos do filme. Em cena aos 10min35s o mestre e líder dos pescadores fala: “Tá tudo separado. Quatrocentos pro patrão, quatro pra mim, e mais cinco para dividir com os homens da rede". Em trecho mais adiante no filme acontece uma discussão entre o representante do dono da rede e o mestre dos pescadores, pois a rede estragou e os pescadores não sabem como irão trabalhar e entregar a quantidade de peixe cobrada pelo dono da rede, demonstrando a exploração dos pescadores mais uma vez. O diálogo ilustra a relação de exploração no trecho do filme (26min16s até 26min44s)

Pois é mestre. O homem mandou dizer que quer peixe de qualquer jeito. A rede é que não pode ficar parada [...] Mas o homem sabe que a rede tá estragada... Não interessa, desculpa você vai dar pessoalmente. O homem só quer saber do peixe e mais nada...Se não der peixe o homem manda buscar a rede [...]. É mais quem puxa a rede somos nós, quando o peixe não vem ficamos sem come. O homem não pensa nisso, ele come todo dia (BARRAVENTO, 1961, n.p.).

Além do posicionamento frente à religiosidade afrodescendente e a crítica a exploração é possível perceber também no desenrolar do filme outros aspectos da religiosidade do candomblé, para além da mistificação alienante. O filme além de provocar uma reflexão crítica ele ao mesmo tempo apresenta a beleza dos ritos afro-brasileiros, com um cuidado plástico ao descrever as danças, a introdução das músicas do candomblé e da plasticidade poética das cenas da roda de samba e da capoeira que de algum modo se tornam um elogio à religiosidade negra e escapam as intenções do cineasta de crítica social e se torna uma experiência etnográfica que revela beleza das expressões culturais apresentadas no filme. Glauber acaba por fazer uma reverência à beleza da ritualística do candomblé quando a representa em longas cenas que vem acrescidas dos sons dos atabaques e das canções entoadas.

Assim ao mesmo tempo que Barravento pode ser vista como uma crítica social e política e uma reflexão sobre a miséria e a mistificação alienante por meio da religião, também pode-se olhar como um registro documental das expressões culturais da comunidade descendente de africanos, de modo que a capoeira, a roda de samba e o candomblé são elementos integradores da cultura local. No filme podemos ver longas cenas e registros sem interrupção que se apresentam na narrativa de modo a ilustrar elementos culturais da identidade brasileira. 
A cena da roda de samba se estende por mais de três minutos (12min08s até $15 \mathrm{~min} 28 \mathrm{~s})$ e aparece sem interrupção de diálogos, somente seguindo numa sequência de cenas intercaladas aleatoriamente em cenas panorâmicas, e detalhes de movimentos dos personagens e do desenrolar da ação da roda.

$\mathrm{Na}$ passagem da roda de samba o cineasta registra em tom documental os detalhes de requebros e gingados dos participantes e a fisionomia, os risos e a alegria na qual cada um é chamado a participar e sambar individualmente no meio da roda. A passagem de um a outro se dá pela umbigada num movimento que marca a troca de posição entre em quem está na roda e quem está dentro da roda de samba, expressando os laços de integração social na comunidade por meio da expressão da dança e da música. Os movimentos da câmera colocam o espectador para observar os movimentos de modo que ele se coloque ora distante ora próximo para poder perceber a dinâmica da interação entre os participantes que se dá pelo ato da umbigada.

A roda representa uma expressão coletiva do grupo social expressando-se como um elemento da identidade cultural brasileira e de integração comunitária. O Samba de Roda traz como suporte determinante tradições culturais transmitidas por africanos escravizados e seus descendentes e essas tradições incluem ainda o culto aos orixás e caboclos pelo Candomblé, e também pela capoeira que também aparecem na obra fílmica de modo a ilustrar a composição dos personagens, suas crenças e modo de vida. Ao mostrar esses elementos na obra fílmica, Glauber também reforça aspectos daquilo que se entende por próprio à brasilidade e ao caráter do cinema que busca o que é nacional.

Nas cenas dos rituais no candomblé, das rodas de capoeira e de samba assim como nas cenas dos trabalhos dos pescadores o movimento das câmeras compõem um movimento coreográfico que ora representa a composição dos movimentos representados, ora também remete ao próprio jogo de movimento da câmera que se expressa na montagem intercalada das cenas e nos oferece uma riqueza de detalhes que expressam um caráter realístico sobre o representado, que aproximam o olhar do espectador, provocando uma sensação de proximidade à cena representada e também às sensações/sentimentos provocados de alegria e descontração na roda de samba ou de apreensão e tensão nas cena dos ritos no terreiro de candomblé. Ou seja, na narrativa fílmica podemos perceber um movimento dos enquadramentos e ângulos que demarcam as intenções do diretor com relação aos sentidos e sensações que os 'objetos' da cena poderão provocar no espectador.

Os planos utilizados no filme vão desde plano geral/aberto, médio, primeiro plano e detalhe, mas o que vai denotar uma singularidade da linguagem glauberiana pode ser vista no modo como ele cria a sua composição e o ritmo com que são alternados. Podemos observar planos panorâmicos ora se apresentando como elementos de transição na narrativa, ora para nos apresentar e contextualizar um olhar que mostra uma teia de relações, uma rede que integra os elementos naturais - como a praia, o mar, vento, areia, recifes, coqueiros, céu - aos elementos humanos - pescadores, vila, rede, atabaques, 
pandeiros, berimbau. O plano aberto nos dá a sensação da ambientação e da relação dos elementos da natureza à religiosidade que será tematizada ao longo da narrativa fílmica. No primeiro trecho do filme logo após o texto introdutório as cenas que se seguem focalizam o céu, praia, mar e na sequência um negro tocando o atabaque. Esse fragmento sintetiza, por meio de um sistema simbólico, o imaginário que estabelece a relação entre as forças da natureza, homem e religião, tendo o céu e o mar como elementos míticos e representando o lugar do sagrado, que se encontra com o elemento humano na espaço da praia e se desdobra num modo de religiosidade representado no signo do negro tocando o atabaque, caracterizando um elemento da religião do Candomblé.

A linguagem documental de Glauber se faz também por meio da escolha de planos fechados que endossam o caráter de realidade e no movimento claro da câmera de aproximar o espectador ao objeto representado para lhe proporcionar percepções mais apuradas, além de sensações e emoções. A escolha dos planos mais próximos, dos pés na areia, das mãos nas cordas, do batuque, dos rostos, dos corpos, da agitação da chegada dos peixes na rede infere na narrativa uma sensação de real sobre o que está sendo representado, mas não somente isso: expressa as intenções do cineasta em mostrar uma realidade social própria ao contexto brasileiro e também de problematizar a necessidade de emancipação e libertação em relação à religião que Glauber acreditava ser um elemento narcotizante e alienador da realidade.

\section{CONSIDERAÇÕES FINAIS}

Essa necessidade de representar o real como um ato político se inicia no primeiro longa-metragem de Glauber Rocha e se desdobrará em outras obras também impregnadas dessa vontade de representar a realidade social, o que fara com a sua estética fílmica seja influenciada pela realidade a ser filmada. Ou seja, o objeto em cena vai interagir com o modo como o cineasta move sua câmera para construir uma representação própria e com tonalidades que tendem a deslocar o espectador do seu lugar comum, ou dito de outro modo provocando rupturas que forjem um pensamento crítico sobre o objeto representado.

Em Barravento - que tem como temática central a crítica ao Candomblé como elemento de uma ideologia que aliena uma comunidade de pescadores no interior da Bahia - Glauber tensiona um olhar curioso e também de encantamento sobre o ritual religioso e o seu sistema simbólico nas longas cenas sem diálogos, somente com trilhas e sons de atabaques com o intuito de introduzir o clima e envolver o espectador. Mas ao mesmo tempo infere um olhar crítico expresso na voz de Firmino nas cenas de diálogos em que ele alerta os pescadores sobre quem os escraviza e os mantém refém da miséria. Tom de denúncia este que também ao final da narrativa se fará na voz de Aruã depois de ser dessacralizado e assumido seu papel como homem e agente de mudança, tal como defende a voz política do cineasta na qual a libertação se dá pela tomada de consciência do homem ao transformar sua realidade. 


\section{REFERÊNCIAS}

AMENGHAL, Barthélémy. Glauber Rocha e os caminhos da liberdade. In: GERBER, Raquel. Glauber Rocha. Rio de Janeiro: Paz e Terra, 1977.

BAZIN, Andre. O cinema - ensaios. São Paulo: Editora Brasiliense, 1985.

BARRAVENTO. Direção: Glauber Rocha. Produção: Rex Schindler e Braga Neto. Salvador: Iglu filmes, 1961. (80 $\mathrm{min}) 35 \mathrm{~mm}$.

BENTES, Ivana (org.). Cartas ao mundo. São Paulo: Companhia das Letras, 1997.

GALVÃO, Maria Rita; BERNARDET, Jean-Claude. Cinema: repercussão em caixa de eco ideológica. São Paulo: Brasiliense, 1980.

NICHOLLS, Bill. Introdução ao documentário. Campinas: Papirus, 2005.

PENAFRIA, Manuela. O Filme Documentário: história, identidade, tecnologia. Lisboa: Edições Cosmos, 1999.

PENAFRIA, Manuela. Perspectivas de Desenvolvimento para o Documentarismo. BOCC - UBI. http://ubista.ubi.pt/ comum/welcome.html , 1999.

PENAFRIA, Manuela. O documentário segundo Bazin: Uma leitura de 'O que é o Cinema?' de André Bazin. In: Doc On-line, No 01, dezembro 2006, 202-210.

ROCHA, Glauber. Revolução do Cinema Novo. Rio de Janeiro: Embrafilme, 1981.

ROCHA, Glauber. O século do cinema. Rio de Janeiro: Alhama/Embrafilme, 1983.

ROCHA, Glauber. Revisão crítica do cinema brasileiro. São Paulo: Cosac Naify, 2003.

ROCHA, Glauber. Experiência 'Barravento’' confissão sem molduras. Diário de Notícias, Salvador, 1969.

SARACENI, Paulo César. Por dentro do Cinema Novo: minha viagem. Rio de Janeiro: Nova Fronteira, 1993.

SALLES GOMES, Paulo Emílio. Cinema: trajetória no subdesenvolvimento. Rio de Janeiro: Paz e Terra/EMBRAFILME, 1980.

SILVA JÚNIOR, Humberto Alves. Glauber Rocha e a estética do cinema documentário brasileiro. In: CÂMARA, Antonio Silva; LESSA, Rodrigo Oliveira (org.). Cinema Documentário Brasileiro em perspectiva. Salvador: EDUFBA, 2013.

SILVA JÚNIOR, Humberto Alves. Glauber Rocha: Cinema, estética e Revolução. Jundiaí, Paco Editorial, 2016.

SIMONARD, Pedro . Origens do Cinema Novo: a cultura política dos anos 50 até 1964. Achegas.net, Internet, v. 9, p. 4, 2003. 
XAVIER, Ismail. O cinema brasileiro moderno. São Paulo: Paz e Terra, 2001.

XAVIER, Ismail. Alegorias do desengano: a resposta do Cinema Novo à modernização conservadora, tese de Livre-docência, ECA/USP, 1989. 


\title{
Title
}

Aesthetics by Glauber Rocha and the interfaces with documentary cinema.

\begin{abstract}
This study intends to reflect on some aspects of Glauber Rocha's cinematographic aesthetics, looking specifically at the confluences established with the aesthetics of documentary cinema. The intention is to discuss how Glauber Rocha appropriates the documentary language to compose his aesthetics of the real and materialize his poetic and political project in a historical and cultural time that became known for the effervescence of the production of an art with an extremely political bias and tone that sought to unveil the reality of the Brazilian people and their identity in the face of North American cultural colonialism. The thinking of the Bahian intellectual and filmmaker is impregnated precisely with the spirit of that time when the production of contemporary art is undergoing a profound change both in Brazil and in Europe, where artists redefined their aesthetics, intertwining them with political causes and, in turn, committed in putting art at the service of social change. The aesthetics of the real that 'blew winds' in the European avant-gardes reverberated in Brazil in the 1960s, being reshaped by the Glauberian perspective, introducing the Brazilian people and their realities into the new Brazilian cinema. The close relationship, and why not say a visceral relationship, between Cinema Novo and the search for an aesthetic of the real leads us to reflect on how the blurring of boundaries between fictional cinema and documentary has reverberated and influenced the composition of the language of Cinema New in Brazil. For the reflections we take as reference Nicholls (2005), Penafria (1999), Xavier (2001) and Simonard (2003).
\end{abstract}

\section{Keywords}

Cinema Novo; Glauber Rocha; documentary.

Recebido em: 09/07/2021.

Aceito em: 24/08/2021. 